\title{
CESPUC
}

\section{A COR, A ARTE E A METÁFORA VISUAL: UM RELATO DE EXPERIÊNCIA DE REVITALIZAÇÃO URBANÍSTICA}

\author{
Morgana Andreia Medeiros Tenório * \\ Edileine Vieira Machado **
}

\begin{abstract}
Resumo
O presente artigo inicia-se por reflexões sobre os impactos e a transformação na vida de duas comunidades revitalizadas por intervenções socioculturais promovidas pelo uso de cores, na forma de arte visual, mais especificamente, as cidades de Medellín, na Colômbia, e Santa Catarina de Palopó, na Guatemala. A partir desse enquadramento geral, o artigo apresenta um relato de experiência do início de um projeto de recuperação de uma região da cidade de Maceió (Alagoas), mais precisamente a comunidade "Vila Redenção". O projeto, intitulado "Intervenções urbanas no Polígono do CESMAC", é desenvolvido por estudantes e professores do curso de Arquitetura e Urbanismo do Centro Universitário CESMAC e conta com a participação efetiva da comunidade local e de uma empresa parceira. A iniciativa focaliza o uso de heurísticas nas produções desenvolvidas, estimulando a capacidade criativa e inventiva dos estudantes. Essa capacidade, manifestada em expressões artísticas visuais, essencialmente metafóricas, é compreendida, neste artigo, à luz do conceito de blending, ou integração conceptual (FAUCONNIER \& TURNER, 2002). O artigo constitui-se, em síntese, na sistematização do relato de uma experiência, em andamento, que institui-se como o campo de pesquisa para a autora.
\end{abstract}

Palavras-chave: Cores. Arte. Metáfora. Blending.

\section{COLOR, ART AND THE VISUAL METAFOR: AN EXPERIENCE REPORT OF URBAN REVITALIZATION}

This article begins by reflections on the impacts and transformation in the life of two communities revitalized by sociocultural interventions promoted by the use of colors, in the form of visual art, more specifically, the cities of Medellín, in Colombia, and Santa Catarina de Palopó, Guatemala. From this general framework, the article presents an experience reported from the beginning of a recovery project in a region of the city of Maceió (Alagoas), more precisely the community "Vila Redenção". The project, entitled "Urban interventions in cesmac polygon", is developed by students and professors of the Architecture and Urbanism course of cesmac university center and has the effective participation of the local community and a partner company. The initiative focuses on the use of heuristics in the productions developed, stimulating the creative and inventive capacity of students. This capacity, manifested in artistic expressions, essentially metaphorical, is understood in this article in the light of the concept of blending, or conceptual integration (FAUCONNIER \& TURNER, 2002). The article consists, in summary, in the systematization of the report of an ongoing experience, which is instituted as the field of research for the author

Keywords : Colors. Art. Metaphor. Blending.

* Doutoranda em Letras na Pontifícia Universidade Católica de Minas Gerais (PUC - Minas). Professora no Centro Universitário Cesmac - Maceió-AL . https://orcid.org/0000-0002-9217-8337.

** Doutora em Educação pela Universidade de São Paulo (FEUSP).Professora na Pontifícia Universidade Católica de Minas Gerais (PUC Minas).Professora no Centro Universitário Cesmac - Maceió-AL. https://orcid.org/0000-0002-0867-4689

Recebido em: 06/12/2019 | Aceito em: 09/12/2019 


\section{A COR E A ARTE}

Ao longo da história da humanidade percebem-se inúmeras manifestações estéticas realizadas por meio das cores. Vários movimentos artísticos foram influenciados por novas técnicas e usos diferentes de sua aplicação. Desde as pinturas nas cavernas até os grafites urbanos modernos, a cor é capaz de ser mais que um fenômeno físico ou psíquico. A cor é capaz de mudar, reduzir ou ampliar um sentimento e gerar uma profunda mudança social. Definir pertencimento e autoestima em situações modificadas pela cor é ser possível imaginar que apenas uma pequena interferência possa impactar em uma profunda mudança no ser humano, em uma região ou até em uma cidade.

As cores podem despertar sentimentos de poder ou de derrota. É possível perceber como isso se dá ao observar os tons azuis das telas de Picasso ou os tons quentes das telas de Monet. Nos dois casos, pelo uso das cores, temos uma voz (a do artista que assina as telas) ecoando significados, imprimindo conceitos simbólicos de uma fase de suas vidas. As cores têm poderes diversos: são capazes de resgatar a história e criar novos padrões urbanos, culturais e sociais. Em consonância com estudos realizados por Farina (1987, p. 27), é possível afirmar que:

Sobre o indivíduo que recebe a comunicação visual, a cor exerce uma ação tríplice: a de impressionar, a de expressar e a de construir. A cor é vista: impressiona a retina. É Sentida: provoca uma emoção. É construtiva, pois tendo um significado próprio, possui valor de símbolo, podendo assim, construir uma linguagem que comunique uma ideia. (FARINA, 1987, p.27).

Frente a essa tese, seria coerente reconhecer que é possível mudar uma comunidade com o uso da cor na arte produzida em espaços públicos urbanos? Pois bem, a resposta a esse questionamento decorre da observação de como pequenas mudanças trouxeram grandes impactos e ressignificaram à vida simples e, por vezes, destruída de algumas comunidades. No mundo contemporâneo encontram-se alguns bons exemplos de favelas, vilas e até mesmo cidades que foram completamente transformadas pelo poder da cor nas artes.

A cidade de Medellín, na Colômbia, é um claro exemplo disso. Durante muitos anos, a cidade foi tomada pela violência e pobreza, descrédito alimentava negativamente a alma da população local, que, sem muitas expectativas de melhorias, se permitia embarcar em uma trágica corrupção mantida pelo poder das drogas dos cartéis mais famosos do mundo.

Nos anos 90, ações governamentais mudaram a forma de conduzir o problema, decidiram inovar na abordagem das intervenções, fazendo-as acontecer de dentro da comunidade, adotando um conceito de "acupuntura urbana", transformando o macro ambiente social a partir do micro, conceito já implantado na cidade de Curitiba, no Brasil.

Mudar o sentimento da população, criar melhorias que conquistem primeiramente os valores do seu povo, resgatando o pertencimento, esse é o desafio assumido por cidades que utilizam a cor e a arte como forma de revitalização da vida urbana. E, assim, se desenvolve, reconhecidamente, uma grande mudança social, motivo de exemplo mundial e cópias ao redor 


\section{morgana Andreia medeiros Temório e Edileime Vieira machado}

2O SEMESTRE DE $2019-$ N. 35

do mundo.

No cumprimento desse objetivo, Medellín foi reconhecida pelo prestigiado The Wall Street Journal como a cidade mais inovadora do ano de 2012.

O direito à cidade é muito mais do que a liberdade individual para acessar os recursos urbanos: é o direito de mudar a nós mesmos, mudando a cidade. Não se trata de um direito individual, uma vez que esta transformação depende, inevitavelmente, do exercício de um poder coletivo para remodelar os processos de urbanização. A liberdade de criar e recriar nossas cidades e a nós mesmos é um dos mais preciosos e dos mais negligenciados dos nossos direitos humanos (DAVID HARVEY, 2012, p. 74).

O princípio é simples. Projetos dessa natureza se estruturam com base em uma matemática que propicie uma grande redução de problemas. Pela diminuição da violência e abertura de novos postos de trabalho, acontece um aumento no espírito de valorização local, que interfere nas relações sociais, no âmago das pessoas e das relações intersubjetivas que estabelecem entre si. Resultado disso é o aumento considerável do equilíbrio social.

Resultados de pesquisa apontam para o fato de que a arte, a cor e mudanças estruturais em regiões metropolitanas marcadas pelo descaso de políticas públicas transformaram a vida de uma das cidades mais procuradas no oeste da América do Sul. Visitar a Colômbia, na atualidade, é poder usufruir do privilégio de realizar uma visita à cidade das cores e das artes, a famosa Medellín. Segundo Sebastian Villa (2015), a moradora colombiana Betty Cárdenas afirma que a arte serve para tornar as pessoas mais íntegras e conscientes de seu lugar no planeta, além de prestar um testemunho histórico e social em suas obras para solucionar os males das comunidades.

É possível citar, em todos os continentes, muitas outras intervenções das cores e artes com impactos sociais relevantes. Recentemente, uma dessas intervenções vem chamando bastante atenção, a vila Santa Catarina de Palopó. Localizada no nordeste do Lago Atitlan, na Guatemala, após a perda de parte de sua subsistência, a agricultura e a pesca, essa vila começou a se afundar em um cenário de profunda pobreza. Por iniciativa de um correspondente internacional da CNN Gautemalicano, Harris Whitbeck, e sua sobrinha, Melissa Whitbeck, um trabalho de transformação foi iniciado com inspiração nas cidades de Burano, na Itália, e a Blue City no Marrocos, outros fantásticos exemplos de cidades coloridas.

A iniciativa que pretende transformar a pequena cidade em uma galeria a céu aberto tem como projeto pintar entre quatro e cinco casas semanalmente, de forma a atingir a meta de 850 casas até 2020 , se utilizando de uma seleção de cores e símbolos da tradicional civilização Maya. Segundo Lola Mendez (2019, p. 30), "esse projeto traz algo ainda mais inovador, turistas podem participar por uma módica quantia de $\$ 500.00$ e assim contribuir para que uma família local possa ter o seu mural de arte executado pelo projeto Pintando's Adopt-a-House". 


\section{COR, A ARTE E O PROJETO}

Com franca inspiração no efeito das intervenções urbanas relatadas anteriormente, em 2018, iniciou-se um projeto na região do campus de uma universidade, na cidade de Maceió/AL, com o objetivo de estabelecer uma proposta de responsabilidade social. Para isso, apostou-se na Vila Redenção, uma comunidade do entorno da universidade, carente, mas muito participativa das inúmeras ações sociais desenvolvidas nos campus. Assim, o projeto "Intervenções Urbanas no Polígono do CESMAC" criou vida. Seu objetivo principal é fortalecer a identidade dos espaços públicos da instituição e da comunidade circunvizinha mediante ações de caráter artístico. Além disso, transformar a região com cores e arte e, com isso, através das dimensões cênicas e imaginárias, procurar ratificar a relação afetiva dos usuários destes espaços (discentes, docentes, colaboradores e comunidade) com o lugar, reforçando o famoso sentimento de pertencimento, além de agregar valores culturais e sociais.

Para a realização da primeira etapa do projeto, foram convidados um renomado artista plástico local, "Suel Damasceno", e alunos voluntários do curso de Arquitetura e Urbanismo do $1^{\circ}$ ao $9^{\circ}$ período. As intervenções teriam um caráter acadêmico no processo de idealização e em sua execução. Nessa etapa, foram pintados símbolos que remetem à cultura local, materializando conteúdos já vistos em sala de aula para aproximar o acadêmico com o real e o regional. Segundo Duarte et al $(2005$, p. 2) "entendemos que projetar um espaço pressupõe não apenas a imaginação desse espaço, mas também a capacidade do indivíduo de interpretar os fatos do mundo e processá-los por meio de formas e volumes". Colocar "a mão na massa" desenvolve os talentos universitários e desperta emoções nos passantes.

Ao longo de um semestre, os alunos estudaram a obra de alguns arquitetos, entre os quais Antônio Gaudi e Ricardo Legorreta, priorizando aqueles cujo trabalho fosse pautado no uso de cores e que servissem de insights no momento da execução das pinturas. Uma pergunta era feita, no entanto: como se processaria o estímulo para esses insights? Segundo o estudo realizado por Weisberg (1999), conforme citado por Florio \& Tagliari (2009, p. 96):

Os insights dependem de sujeitos que usam processos cognitivos convencionais, com a transferência analógica aplicada ao conhecimento já armazenado na memória. $\mathrm{O}$ insight ocorre quando os conhecimentos armazenados na memória do sujeito, em dadas situações, emergem por conexões inesperadas na mente, culminando em ideias criativas.

Compreendido em uma perspectiva cognitiva, como é possível observar pelas ideias de Turner (2014), nossos processos mentais são uma rede de conexões costuradas entre si, que produzem mais espaços e mais conexões quando pensamos em algo novo. Segundo Turner 2014, p.05 "Mental spaces are sewn together in what we might think of as a mental web. A mental web has mental spaces and connections between them, and we build more mental spaces and more connections as we think about something".

Dessa forma, foi adotado o uso de heurísticas para aguçar a curiosidade e a criatividade dos alunos envolvidos. Então, sem regras, permitiu-se que seguissem livres em uma viagem de 


\section{CESPUC}

\section{Morgana Andreia medeiros Temōrio e Edileime Vieira machado}

explosões expressivo-cognitivas. Para Florio \& Tagliari

Ao estabelecer uma rede de associações entre diferentes ideias, o raciocínio lógico e as ideias convencionais dão lugar ao raciocínio analógico, propiciando a produção de numerosas ideias. (...) É importante destacar que heurísticas são ações, e não regras, que facilitam a descoberta. (FLORIO \& TAGLIARI, 2009, p.96).

As figuras de 1 a 4, a seguir, documentam o processo de criação e de produção estética dos sujeitos envolvidos no projeto de intervenção. Como é possível observar, todo o processo se dá de maneira a privilegiar as dimensões subjetivas e intersubjetivas da criação artística e de sua respectiva expressão simbólico-emocional.

Figura 1 - no atelier de desenho, produção de moldes para as pinturas.

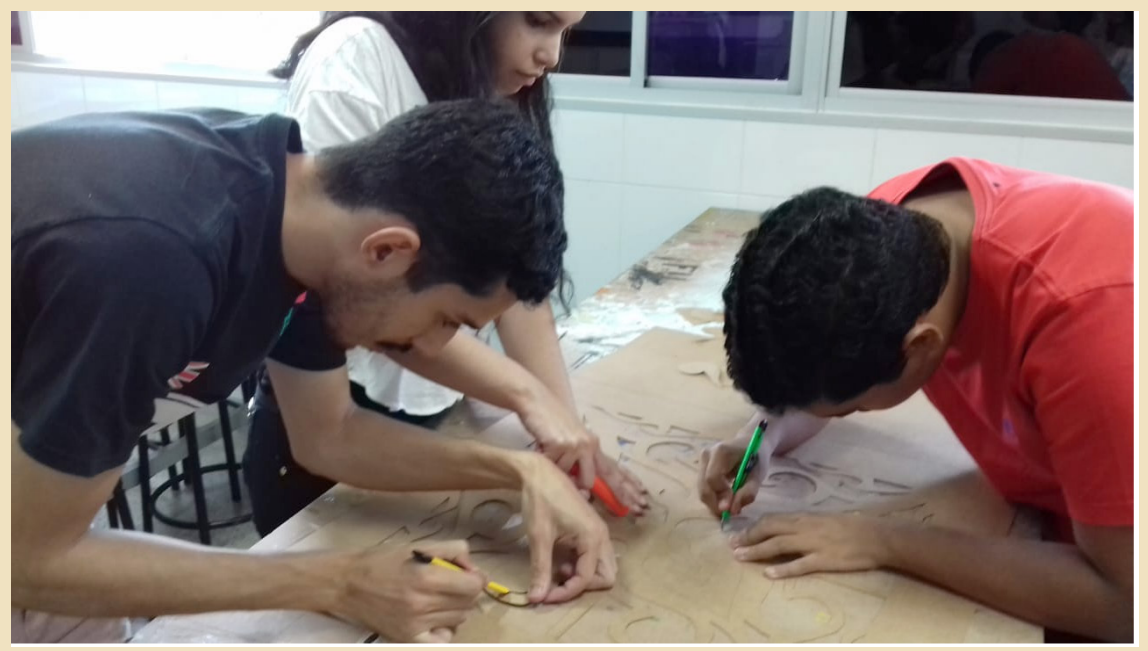

Fonte: Autora.

Figura 2 - executando as pinturas inspiradas em símbolos de Alagoas.

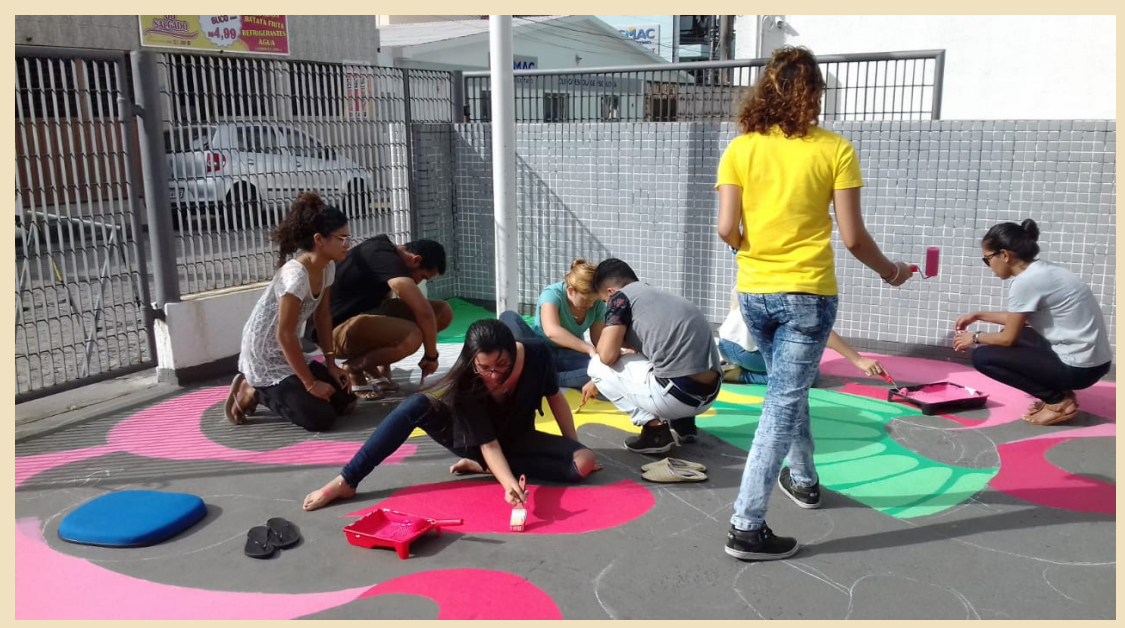

Fonte: Autora. 


\section{CESPUC}

Figura 3 e 4 - pinturas realizadas por alunos da instituição.

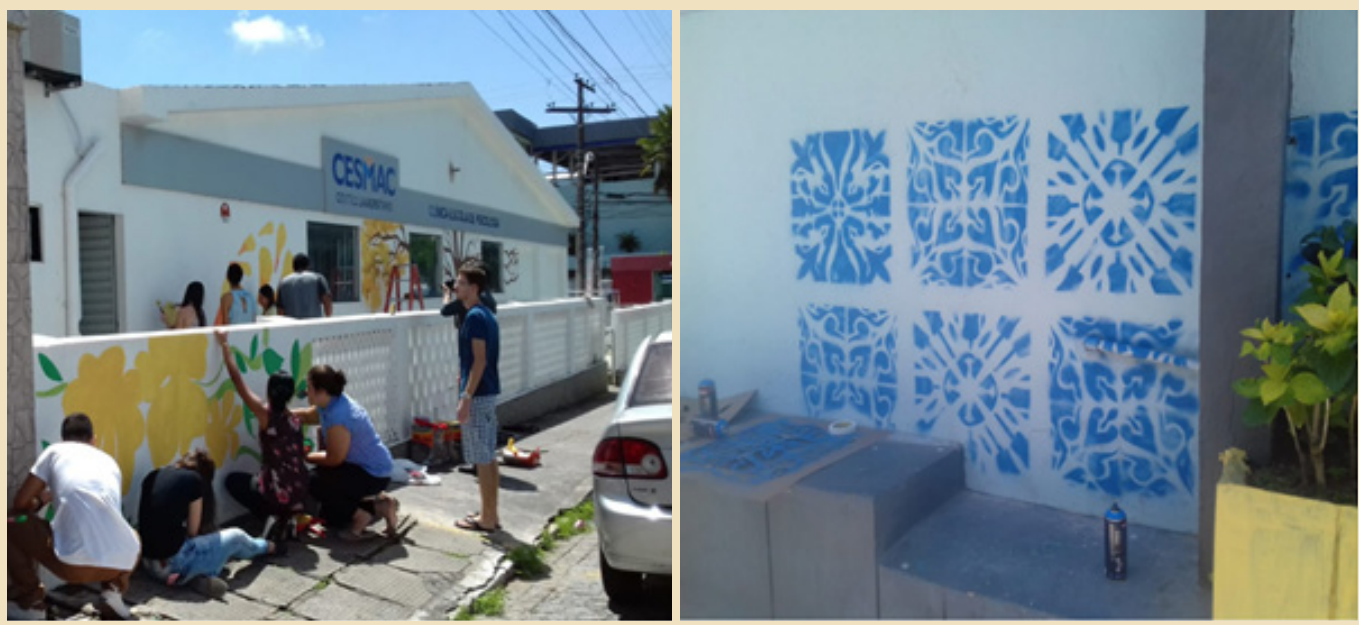

Fonte: Autora.

Através do projeto, avançou-se com as intervenções pelo entorno do campus da universidade. Ao longo do ano de 2018, foram pintadas ruas, paredes e pisos com símbolos e cores bem regionais e, nos primeiros meses de 2019, iniciou-se a segunda etapa do projeto que contempla as casas da comunidade Vila Redenção. Em uma experiência muito especial, para os professores e estudantes do curso de Arquitetura, realizar atividades de extensão comunitária traz uma dimensão afetiva bastante significativa ao processo formativo acadêmico-profissional e humano.

Na segunda etapa, o projeto foi contemplado com o patrocínio de uma empresa de tintas local $^{1}$, que ofereceu as tintas para a pintura de 40 (quarenta) casas da comunidade. Com o apoio dessa empresa parceira, foram convidados os estudantes dos cursos da universidade. $\mathrm{O}$ convite inicial aberto a todos os estudantes que apreciam arte, foi feito com o objetivo de que os interessados participassem de uma oficina e uma palestra sobre cores, intitulada "as cores e sua aplicação". Dessa forma, resultaria em uma proposta para as pinturas das fachadas das casas da comunidade como um concurso de arte. Assim, seguiu-se, uma vez mais, com a proposta de trabalhar com heurísticas, apresentando vários exemplos de intervenções feitas com arte em comunidades como estratégia para motivá-los através de estímulos visuais e possibilitar o fluir da capacidade de acharem soluções inovadoras e criativas para problemas encontrados na comunidade.

Assumindo a tese da "Origem das Ideias" advogada por Turner (2014), é possível compreender que o quão mais estimulados esses estudantes forem, melhores os resultados alcançados nas propostas. Isso significa que a dinâmica do processo criativo, em uma perspectiva cognitiva, se dá pela evocação de formas de conhecimento já experenciadas e, dessa forma, já existentes na memória e sua integração em uma operação cognitiva básica denominada blending. Segundo Turner

1 A empresa Casas Jardim, acreditando nos objetivos e na metodologia do trabalho desenvolvido no âmbito do projeto, tornou-se uma parceira de fundamental importância para a sua realização. Maiores informações sobre a instituição podem ser acessadas pelo site: www.casasjardim.com.br. 


\section{CESPUC}

Blending allow us to perform three characteristic mental feats. Because of blending, we are able to: develop new ideas out of old". (...) We frequently find in blending that an existing, conventional blend as an input mental space to the new blend. (TURNER, 2014, p. 131)

As figuras 5 e 6, a seguir, registram o momento em que o resultado do concurso é apresentado à comunidade.

Figura 5 e 6 - Oficina sobre cores e elaboraçao da porposta de pinturas para a comunidade.
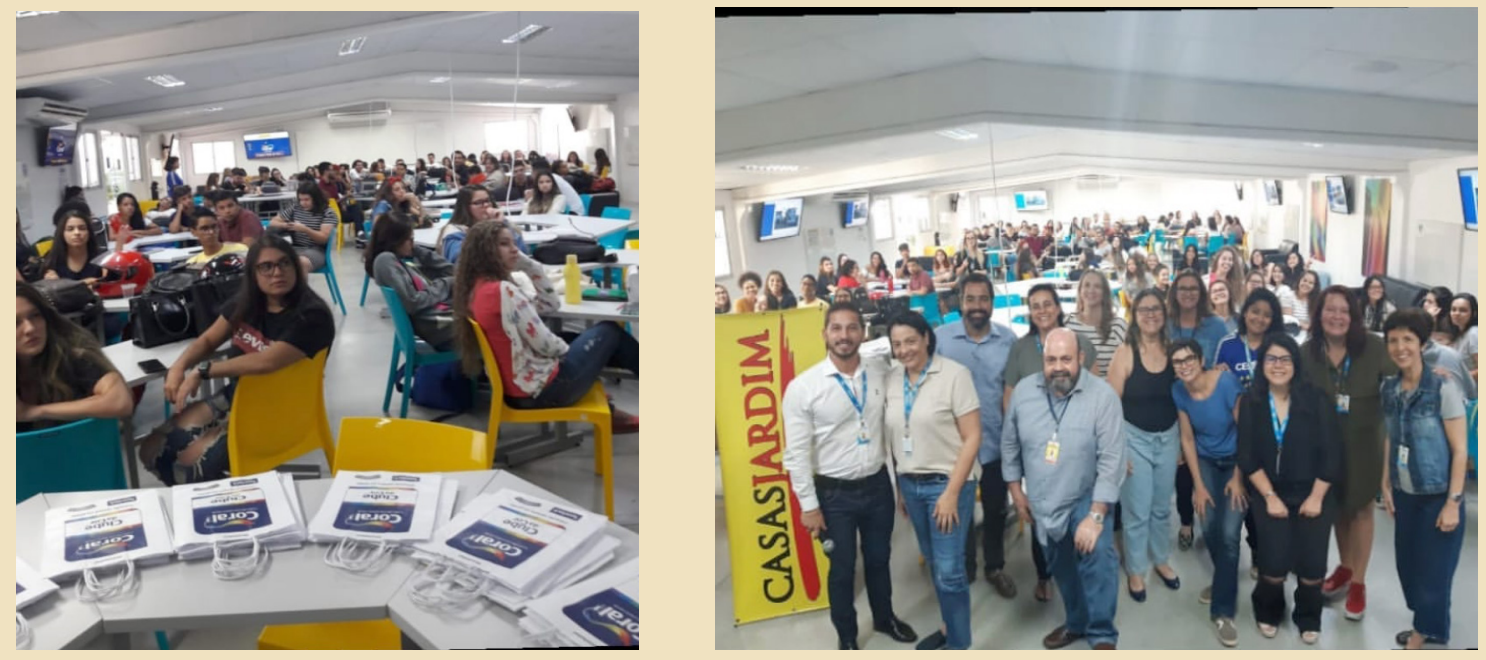

Fonte: (MEDEIROS, 2019)

Por ocasião do concurso, mais de 100 (cem) estudantes participaram da oficina e, em meio a diferentes e criativas propostas, juntamente com a opinião dos próprios moradores das casas, escolheu-se a proposta que representava os símbolos da cidade de Maceió/Al.

O concurso trouxe como resultado um conjunto de projetos que podem ser compreendidos à luz do conceito de "metáforas arquitetônicas". Segundo Florio \& Tagliari

A metáfora arquitetônica normalmente se alimenta de ideias, imagens, princípios de organização de outras disciplinas, de outros esforços criativos. Entretanto, não são escolhidas aleatoriamente, ao contrário, são definidas a partir da esfera de conhecimentos, pensamentos e da cultura de seu tempo (FLORIO E TAGLIARI 2009, p.97).

Com esse conceito em mente, podemos compreender a opção por uma proposta rica em cores, que relembrasse em detalhes a cultura local e seus símbolos pitorescos como solução para o projeto a ser desenvolvido na comunidade. Dessa forma, considerando que metáforas arquitetônicas se estruturam e manifestam, de maneira artística, através das nossas experiências sociais e emocionais, o projeto visou, desde o princípio, a busca de uma experiência que permitisse ao morador uma aproximação confortável do sentimento de pertencimento à sua comunidade. Nessa experiência, a sua casa, o seu bairro, a sua cidade poderão ser percebidas (e sentidas) de maneira mais aproximada e mais valorizada. 


\section{A cor, a arte, o projeto e a METÁFORA como experiência.}

Neste momento, outras perguntas podem ser feitas no sentido de orientar o meu olhar, como pesquisadora que, partindo do campo da Arquitetura, busca definir um objeto de estudo no campo da Linguística e, mais precisamente, dos estudos discursivos. Entre esses questionamentos: como podemos descrever e explicar uma experiência humana (social, cultural), marcada pelo uso da cor e das artes? Como podemos explicar a forma como essa experiência afeta os sujeitos sociais nela implicados?

Como resposta provisória a esses questionamentos, a hipótese com que trabalho é a de que o que está em cena é o fenômeno da metáfora, ou seja, o processo de metaforização (a ação de metaforizar) é um aspecto estruturador da experiência de revitalização do espaço público urbano, com base no uso da cor e, especialmente, em manifestações artísticas como a pintura e o grafite.

Segundo Duarte (2005, p. 2), a "metáfora" se remete etimologicamente ao ato de transportar (de um sentido para outro) e o espaço, a arquitetura e lugares imaginados se prestam, "como luvas", para receberem significados de sentimentos abstratos transportados em busca de explicação. Dessa forma, manifestamos, por exemplo, a nossa percepção, compreensão e manifestação linguística de espaço (centro-periferia) e a nossa percepção, compreensão e manifestação linguística de outros conceitos. Discursivamente, podemos ter essa experiência manifestada em enunciados metafóricos tais como: "você é o centro da minha vida" e "aquele foi um depoimento periférico".

Com base nesses argumentos, podemos reconhecer o quão é importante a busca de compreender como as metáforas são criadas e como são apreendidas pelos seres humanos? As metáforas, manifestadas em diferentes linguagens e sistemas simbólicos, são importantes instrumentos na formação do inconsciente psíquico-cognitivo, o que pode ser flagrado na manifestação de satisfação, quando o ser humano está afetado positivamente pela arte, ou na tristeza, quando a mesma desencadeia a experiência de algum sofrimento ou dor? Mas o que, realmente, são as metáforas?

Para Simon Unwin, as metáforas seriam a transformação ou tradução de uma coisa em termos de outra, um fator na geração de ideias, na e para a arquitetura ou outras disciplinas. Nos termos do pesquisador: "Metaphor is when the mind translates one thing into terms of another. "It is a factor in the generation of ideas, in architecture as in other disciplines". (UNWIN, 2019, p. 8).

Segundo Gurgel (2012, p. 100), baseado em Danto (2007, p. 32) que denomina "metáfora" aquilo que se passa, o sentido que se constrói, na ou a partir da representação pictórica (ou plástica), uma vez que, assim como se dá nas metáforas linguísticas, nenhuma "paráfrase ou resumo vai conseguir exercer um poder equivalente ao da obra (de arte, pictórica) sobre o espírito do observador que participa da constituição dela".

Assim, as metáforas passam a ser compreendidas como estruturadoras das nossas experiências cognitivas com formas de artes as mais diversas. Essas representam uma exploração 


\section{CESPUC \\ 2O SEMESTRE DE $2019-$ N. 35}

\section{morgana Amdreia medeiros Temōrio e Edileime Vieira machado}

de habilidades cognitivas básicas, tais como percepção, atenção e memória² ${ }^{2}$ do nosso implícito conhecimento do mundo, além de expressarem as peculiaridades de um determinado período cultural.

Simon Unwin defende a tese de que o ar da língua que respiramos está repleto de metáforas, que elas nos ajudam a identificar, caracterizar, assimilar nossa percepção e conhecimento de mundo, pois essa é onipresente. Segundo o pesquisador, "The air of the language we breathe is infused with metaphor. We identify, characterize, assimilate, make sense of things by metaphor. Metaphor is ubiquitous. It has an extraordinary powerful influence on our perception and understanding of the world". (UNWIN (2019, p.4).

Sendo assim, podemos compreender que as metáforas são estruturadoras da experiência estética humana, uma vez que participam do processo de construção, conceituação e criação cognitiva das manifestações artísticas, das obras de arte, bem como da leitura que fazemos delas, a depender do conjunto de conhecimentos que tenhamos corporificado na forma de memórias. Essa tese pode e deve ser aprofundada à luz de estudos cognitivistas do fenômeno da metáfora, como os realizados por Black (1962) e Lakoff e Johnson (1980). Ao refletir sobre a relação indissociável entre metáfora e manifestação artística, Parsons, afirma que:

As obras de Max Black e de Lakoff e Johnson, em conjunto, oferecem uma maneira de interpretar os significados de obras de arte através de metáforas. As metáforas visuais são encontradas em diversos níveis nas pinturas: no nível pictórico, na própria representação, em estilos de pintura e em elementos puramente visuais dessa mídia. Elas têm a possibilidade de ser diferentes das linguísticas, pois, muitas vezes, podem ser lidas de trás para frente, e várias metáforas podem coexistir na mesma obra sem gerar confusão. Por esses motivos, as metáforas visuais são ser mais sugestivas e ambíguas do que as linguísticas (PARSONS 2011, p. 292).

Com essa breve compreensão do processo metafórico, percebe-se que as metáforas visuais, também discutidas pelo filósofo Arthur C. Danto (1924-2013), mas pouco ainda exploradas com base em uma possível interseção entre estudos que realizam na relação entre a Arquitetura e a Linguística e a Semiótica Cognitiva, podem e devem ser estudadas considerando-se o processo de interpretação das cores e das artes. Isso, pelo fato de que a metáfora está presente em todo o processo de comunicação humana estabelecido por imagens. Nessa medida, também no processo de expressão artística desenvolvido por este projeto e relatado neste artigo.

Através do desenvolvimento desse projeto, espera-se que o mesmo traga vida ou novas formas de compreensão e experienciação emocional de uma comunidade socialmente esquecida pelo poder público. Além disso, que oportunize, aos estudantes e professores implicados em sua realização, o desenvolvimento e a compreensão de suas habilidades cognitivas (perceptuais, atencionais, memorialísticas), de suas capacidades criativas, inventivas e de suas experiências emocional. Esses são aspectos que estão na base do projeto de doutorado da autora, em andamento.

2 Sobre o assunto, conferir CAVALCANTE $(2002,2007,2015,2016)$. 
20 SEMESTRE DE $2019-$ N. 35

\section{BREVES CONSIDERAÇÕES FINAIS}

Percebemos através desse estudo que um longo caminho ainda nos separa da compressão do processo psíquico-cognitivo estabelecido entre A ARTE, À METÁFORA, A LINGUAGEM e nós mesmos. Se somos, frutos do que vivemos, e se, para compreendermos o mundo ao redor precisamos vivenciá-lo, então entendemos que todos os estímulos, sejam eles promovidos por heurísticas ou insights, são todos extremamente necessários ao processo de construção da nossa percepção sobre o nosso EU e o EU social. Neste trabalho apropriamo-nos de processos cognitivos básicos, antes utilizados, mas não compreendidos, como o blending, para perceber as metáforas. Somos o que somos e aprendemos, e as metáforas, são inerentes ao ser humano, consequência da consciência e da natureza do nosso cérebro e corpo no mundo que habitamos. Segundo Ortiz (2011), "Estas metáforas forman parte de nuestro inconsciente cognitivo, son inherentes al ser humano, consecuencia de la naturaleza del cerebro, el cuerpo y el mundo que habita".

Este projeto do curso de arquitetura é, no entanto, uma excelente oportunidade para que os estudantes possam pensar e criar propostas para os moradores de uma região tão próxima a vida universitária deles. Um momento propício para formar o vínculo emocional e profissional em uma perspectiva bem social, um laboratório vivo de experiências e vivências. Dessa forma, o processo metafórico serviu como ferramenta fundamental na compressão do significado das intervenções artísticas na vida desses personagens envolvidos no projeto, pois como estruturadoras da experiência estética humana, a metáfora constrói e resgata as memórias de uma sociedade. 


\section{CESPUC}

\section{REFERÊNCIAS}

BLACK, M. Models and Metaphors. Ithaca, New York: Cornell University Press, 1962.

CAVALCANTE, Sandra M. S. Teorias de Metáfora. In CAVALCANTE, Sandra. A Metáfora no Processo de Referenciação. PUC Minas. 2002. Dissertação de Mestrado. Disponível em: (https://www.researchgate.net/publication/331502651_->. Acesso em: 15 out 2019.

CAVALCANTE, Sandra M. S Dimensões sociocognitivas do fenômeno da intertextualidade. In Hugo Mari, Ivete Walty, Maria Nazareth Fonseca. (org.). Ensaios sobre Leitura 2. Belo Horizonte: Editora PUC Minas, 2007, v. 2, p. 124-147.

CAVAlCANTE, SANDRA M. S.; MILITAO, J. A. Emotions, Attention and Blending. In: Giorgio Marchetti, Giulio Benedetti, and Ahlam Alharbi (Pozzo d'Adda, Italy, and others). (org.). Attention and Meaning: The Attentional Basis of Meaning. New York: Nova Publishers, 2015, p. 189-206.

CAVALCANTE, S.; FERREIRA, Luciane; GUALDA, Ricardo. Metáfora: diferentes perspectivas. Revista Scripta. Centro de Estudos Luso-afro-brasileiros. PUC Minas. v. 20, n. 40. 2016. Disponível em: ‘http://periodicos.pucminas.br/index.php/scripta/issue/view/772 . Acesso 13 out 2019.

DANTO, Arthur C. The transfigured: concluding remarks. In: Online conference in aesthetics: Arthur Danto's transfiguration of the commonplace - 25 years later, 2007, p. 33-34. Disponível em: http://vanderbilt.edu/AnS/philosophy/events/.OCA/DantoDantoConference.pdf). Acesso em: 15 out. 2019.

DUARTE, C. et al. Projeto e metáfora: explorando ferramentas de análise do espaço construído. Projetar 2005 - II Seminário sobre Ensino e Pesquisa em Projeto de Arquitetura. Rio de Janeiro: Fau/UFU, 2005.

FLORIO, Wilson, TAGLIARI, Ana. Projeto, criatividade e metáfora. Arquitetura Revista - Vol. 5, n 2:92-110 (julho/dezembro 2009).

GURGEL, Diogo. A metáfora na obra de arte: estudo 1. Revista eletrônica de estética Viso · Cadernos de estética aplicada. n ${ }^{\mathrm{O}}$ 12, jul-dez 2012, p. 100.

HARVEY, David. Paris, Capital of Modernity. New York: Routledge, 2003.

LAKOFF, G.; JOHNSON, M. Metaphors we live by. Chicago: University of Chicago Press, 1980.

MENDEZ, Lola (2019). Paint the town Blue. Hemispheres. 12 ago 2019, p. 30.

ORTIZ, Maria. La Metáfora Visual Corporeizada: Bases Cognitivas del Discurso Audiovisual. Zer 16-30 (2011), pp. 57-73.

PARSONS, Michael. Interpretação da arte através de metáforas Educação, Porto Alegre, v. 34, n. 3, p. 286-292, set./dez. 2011. 


\section{CESPUC \\ 2O SEMESTRE DE $2019-\mathrm{N} .35$}

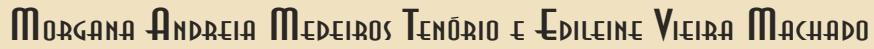

TURNER, M. The Origin of Ideas: Blending, Creativity, and the Human Spark. New York: Oxford University Press, 2014.

TURNER, Mark. The Origin of Ideas: Blending, Creativity, and the Human Spark. New York: Oxford University Press, 2014.

UNWIN, Simon. Metaphor: an exploration of the metaphorical dimensions and potential of architecture.2019.

VILLA,Sebastian. "Arte como agente de mudança em Medellín: 10 exemplos". El Pais, Brasil, 07/09/2015. Cultura. Disponível em<https://brasil.elpais.com/brasil/2015/09/07/ cultura/1441621685_465826.html >. Acesso em: 10 out 2019. 